\title{
Estimation of Direct Normal Irradiance at Antarctica for Concentrated Solar Technology
}

\author{
Irena Balog $\left.{ }^{1, *} \mathbb{(}\right)$, Francesco Spinelli ${ }^{1}$, Paolo Grigioni ${ }^{2}{ }^{\circledR}$, Giampaolo Caputo ${ }^{1}$, \\ Giuseppe Napoli ${ }^{1}$ and Lorenzo De Silvestri ${ }^{2}$ \\ 1 ENEA Casaccia Research Center, DTE-STSN, via Anguillarese 301, 000123 Rome, Italy \\ 2 ENEA Casaccia Research Center, SSPT-PROTER, via Anguillarese 301, 000123 Rome, Italy \\ * Correspondence: irena.balog@enea.it
}

Received: 27 June 2019; Accepted: 10 July 2019; Published: 11 July 2019

\begin{abstract}
The estimation of the average daily, monthly and annual direct normal solar irradiation (DNI) was done in the region hosting the Mario Zucchelli Station, in the bay of Terra Nova (Antarctica). Estimates are based on measurements of direct normal (DNI), horizontal global (GHI) and horizontal diffuse (Diff.HI) irradiations, observed by a solar-metric acquisition station installed during the XXVIII scientific expedition carried out in the austral summer 2012/2013 as part of the National Plan of Research in Antarctica (PNRA). The contemporary observations of all three irradiations allowed the setting up of the model for the estimation of the DNI starting from the values of the GHI only, validated for the weather conditions of the Antarctic region. Subsequently, the long-time data reconstruction of the DNI values thanks to the availability of several years' hourly measurements of GHI at the Mario Zucchelli base has been carried out using the meteorological acquisition data installed both at the base and in places scattered around it. The final results make feasible the estimation of solar potential for concentrated solar technology according to long measurements of GHI. Overall, we propose a clean technology based on a renewable power plant and a specific example with a tendency toward a decreased human carbon footprint in the atmosphere of this protected area.
\end{abstract}

Keywords: Antarctica; solar radiation observations; direct normal irradiance; global horizontal irradiance; diffraction model; concentrating solar technology

\section{Introduction}

Since 1985, with the National Program of Research in Antarctica (PNRA) Italy has been engaged in missions in Antarctica; ENEA, the Italian National Agency for New Technologies, Energy and Sustainable Economic Development, is entrusted with the task of implementation and logistics, as well as organizational responsibility in the operational areas. Due to its geographical position, physical characteristics, distance from pollution sources and the almost total absence of anthropogenic disturbances, Antarctica is one of the most privileged places for the global observation of the planet. The climatic history of the last 10,000 years is recorded both in sediments and in continental ice. The answers and the causes of past climate change and variations in the sea level are the basis for understanding the causes of very short-term climatic variations and the influence of anthropogenic effects on the global environment. Italy (ENEA) maintains two permanent scientific bases in Antarctica: Mario Zucchelli Station (MZS, coordinates $74^{\circ} 41^{\prime} \mathrm{S}$ and $164^{\circ} 05^{\prime} \mathrm{E}$ ) in the bay of Terra Nova overlooking the Ross Sea in the portion of the continent attributed to New Zealand and Concordia (DC, coordinates $75^{\circ} \mathrm{S}$ and $123^{\circ} \mathrm{E}$ ) in the interior of the continent about $1200 \mathrm{~km}$ from MZS. MZS (Figure 1) is the reference point for all the Italian scientific activities in Antarctica. 


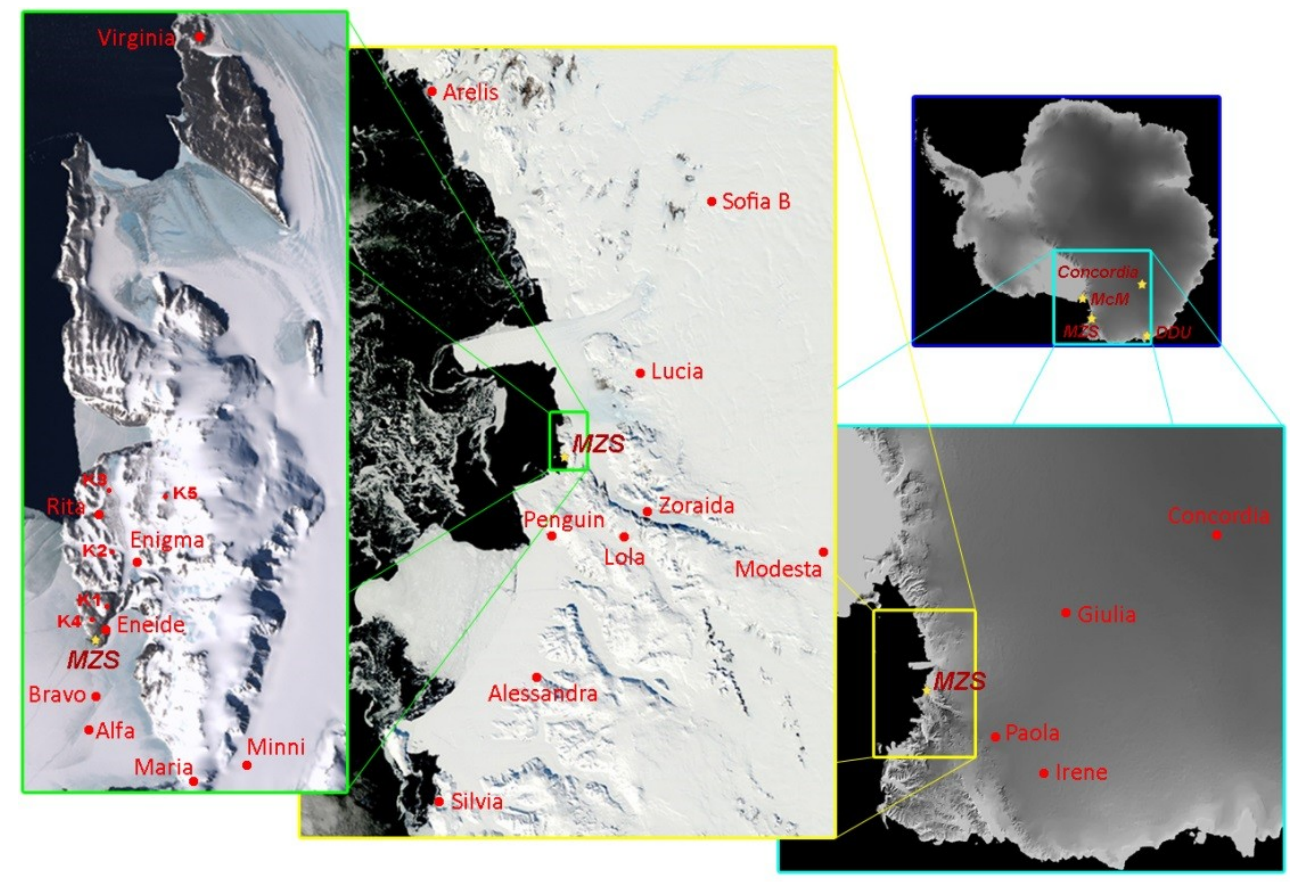

Figure 1. Map of Antarctica with the locations of the Italian Automatic Weather Stations [1].

The management of meteo-climatological observations establishes one Italian activity conducted in Antarctica. The first installed automatic meteorological station was Eneide, at MZS. The purpose of Antarctic observations is to contribute to the monitoring of global climate change in an environment considered by the international scientific community to be very sensitive to changes in the climate. The Automatic Weather Station project (AWS) counts among several National Antarctic Programs in order to produce a vast observational network created specifically for the polar environment [2]. Today the Italian observation network includes 23 stations inside the AWS project [1] that have been positioned in the Antarctic territory during the different expeditions carried out so far. Sixteen of the AWSs are operational year round, while five are seasonal and dedicated to the flying activities near the scientific bases of MZS and DC, one is mounted on the survival modules of the crossbar of the International Trans Antarctic Scientific Expedition (ITASE) and another one is positioned on board the Italica oceanographic ship. The AWS are all based on VAISALA acquisition systems. The physical quantities sampled are generally temperature, humidity, pressure, wind speed and direction and in some stations global solar irradiance [1,3]. All observational stations are calibrated regularly inside the AWS program conditions.

In the austral summer months (September to February), when the permanent meteorological base Mario Zucchelli is mostly crowded with scientific staff, electrical demand grows. Unfortunately, in this privileged place for climatic and global warming studies, the scientific observatory still uses fossil fuels and low efficiency engines for heating and electricity demand that increase the carbon footprint in the atmosphere. In order to reduce carbon production in this protected area, we propose a renewable power plant that uses Concentrated Solar (CS) technology that could satisfy to some degree the electricity requirements in summer months. ENEA, since 2001, has been studying CS plants and has developed an innovative CS technology. Mentioned technology needs evaluation of solar radiation potential.

To investigate the possibility and feasibility of the specific location for a possible CS plant, the application starts from the site characterization, not only in terms of basic meteorological parameters but also in the characterization of the solar radiation component, and specifically direct normal irradiation (DNI). The feasibility study needs a constant and validated set of observations over a long period of time (for example, 10 years) [4,5]. Along the XXVIII scientific expedition, the high frequency 
observations of all three solar components were obtained, with the solar-metric acquisition station that provided the possibility to produce an evaluation and feasibility study for a CS plant in the Antarctic area. A novelty of this contribution is that we propose a DNI estimation model based on a strongly validated set of observed data (over 65 days) in all three solar components, where final contribution is the estimation of DNI according to available long dataset of global horizontal irradiation (GHI) observations and where a fine-tuned model is then applied to the entire dataset in Antarctica.

This paper is organized as follows. In Section 2, we present the materials and methods used in this study where a short overview of the Antarctic climate and model methodology is proposed, followed by model validation. Section 3 contains the results and model evaluation where the effective case study where CS plant is considered. Discussions are presented in Section 4 with short summary and Section 5 completes this paper with concluding remarks.

\section{Materials and Methods}

\subsection{The Antarctic Climate}

The climate of the Antarctic continent is strongly influenced by astronomical factors, its geographical position, the average altitude and its ice cover. Since the Earth, during the winter season of the southern hemisphere, is at the maximum distance from the Sun, this season is longer than in the northern hemisphere. Therefore, this long polar night and the Sun's low inclination angle makes Antarctica a less heated continent even in the summer. In addition, the surface is almost completely covered by ice or by snow, which reflects most of the incident solar energy. Moreover, the average altitude of the continent exceeds $2000 \mathrm{~m}$, contributing to a reduction in the thickness of the atmospheric troposphere, which normally acts as a heat source.

All these factors make Antarctica the coldest place on Earth, with a very short summer and very long winter, where temperatures reach winter minimum values even in autumn. In winter, the average temperatures range between $-20^{\circ} \mathrm{C}$ in the coastal strip and $-70{ }^{\circ} \mathrm{C}$ in the continent, while in the summer the average temperatures range between $0{ }^{\circ} \mathrm{C}$ along the coast and $-35^{\circ} \mathrm{C}$ in the continent.

The orography of the continent presents a vast central elevated landform, the plateau, with a slope towards the ocean. MZS, located on the coast of the Ross Sea, is separated from the plateau by the Transantarctic Chain. The heat loss caused by surface albedo acts in the formation of an intense thermal inversion near the ground, with the consequent formation of very cold air that moves from the plateau by gravity towards the coastal areas, forming the katabatic winds. These winds, which often exceed $100 \mathrm{~km} / \mathrm{h}$, give rise to snowstorms that can persist for long periods; once they reach the coastal strip, they encounter more humid and warm air masses generating violent disturbances. Precipitation, in Antarctica, is generally scarce and more concentrated along the coastal strip, so that we may consider the Antarctic continent a cold desert. The area surrounding MZS is in fact considered one of the windiest places on Earth.

The trend of average monthly temperatures shows a maximum corresponding to the months of December and January, when temperatures are close to $0{ }^{\circ} \mathrm{C}$. A sudden drop in temperatures occurs between February and March, reaching average values of around $-20^{\circ} \mathrm{C}$ in April. The temperatures continue to reach minimal values until July and August with the lowest temperatures recorded throughout the year, reaching $-22{ }^{\circ} \mathrm{C}$ in average values with extreme peaks of $-40{ }^{\circ} \mathrm{C}$. In September the temperatures start to increase, which continues until December. The predominant winds measured at MSZ are oriented in a west and north-west direction. Those wind directions are the most intense winds coming from the glacial valleys of the Reeves and Priestley glaciers, the area that connects the Antarctic Plateau with the Ocean. In general, in this area, eastern and southern winds are rare. Days with no wind are very frequent [3]. 


\subsection{Description of the Solar Metric Station and Observations}

As part of the XXVIII scientific expedition of the PNRA in the austral summer season (October 2012/February 2013), ENEA oversaw the installation at MZS of a solar-metric acquisition station with the aim of carrying out high frequency and strong validated observations to create a data repository for solar irradiance modeling in the Antarctic region. The solar-metric station, produced by EKO Instruments, is equipped with three sensors-a single pyrheliometer and two pyranometers-for the independent measurement of the fundamental quantities for the purpose of characterizing the solar radiation on the ground: Global irradiance on the horizontal plane (GHI); Diffuse irradiance on the horizontal plane (Diff.HI) and Direct irradiance on the normal plane to the Sun's beams (DNI).

The instrumentation also includes a Sun tracker, a device with moving parts that instantly detects the position of the Sun and allows the instrumentation to be aimed in the direction of the solar disc. The measurement error with the Kipp and Zonen CMP11 instrument is $\pm 3 \%$ (Figure 2), with a width of spectrum ranges is from 335 to $2200 \mathrm{~nm}$, while the sensitivity of the instrument ranges from 4 to $6 \mu \mathrm{V} \cdot \mathrm{Wm}^{-2}$. The station is equipped with an automatic data acquisition system that stores the observations, mean value and the average square deviations of each quantity. All the data are recorded on an internal memory module capable of holding the data acquired for a period of several months.

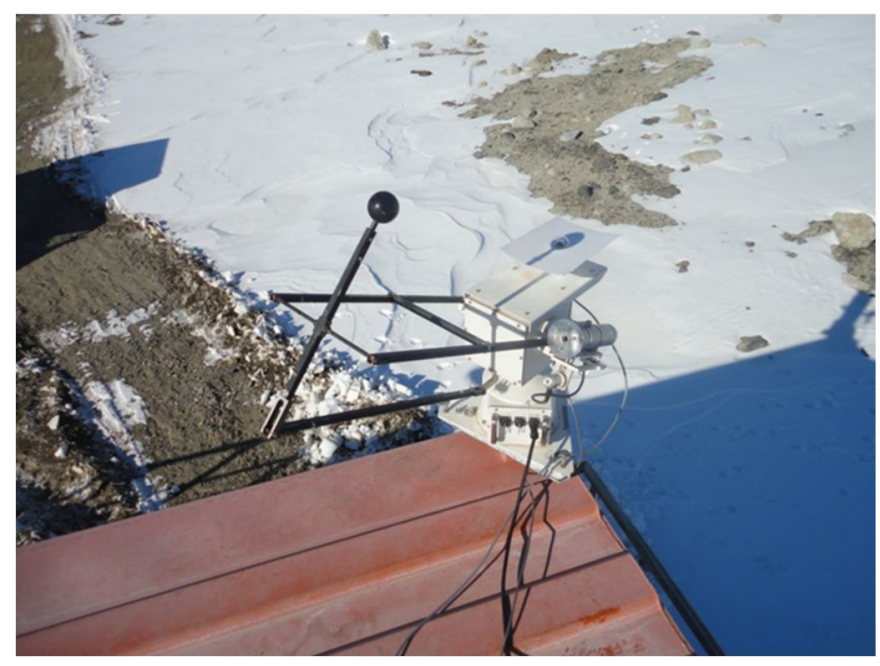

Figure 2. Photo of Solar-metric station of the instrument at Mario Zucchelli Station.

\subsection{Data Analysis and Model Development}

The solar-metric instrumentation control unit was programmed to perform a measurement of the three solar components, DNI, GHI and Diff.HI, each minute, while the data acquisition was recorded with a frequency of one record every five minutes. In particular, every five minutes, for each of the three irradiation components, the average and the mean standard deviation values (MSD) of the five consecutive measures in the interval were recorded. In the model construction of the DNI estimation starting from the GHI, only the averages value were used, while the MSD were used to check (and potentially discard) those average values that seemed far-fetched. Throughout 65 days of constant observations, 18,709 specific data elements were recorded which corresponds to 288 records per day.

18,545 of the recorded data elements from the entire data set are related to diurnal intervals that can be used for the estimation of the DNI. The reason the records of daily observations with respect to the total observations are so preponderant is that beyond the parallels of the polar circles, the day duration increases considerably in the summer season. The Sun in this area remains uninterruptedly beneath the horizon (the polar night). At the latitude where the Mario Zucchelli base is located, sunrise and sunset are present until 3rd November; then, from 4th November until 7th February, the Sun remains above the horizon for the entire $24 \mathrm{~h}$ period. 
Conversely, it should be noted that although the days are long, in reality the Sun rises relatively little above the horizon during the day and this effect is much more pronounced as we move towards latitudes close to the poles. The phenomenon can be shown by calculating the Sun's maximum elevation during the day [6], for all the days of the year (Figure 3).

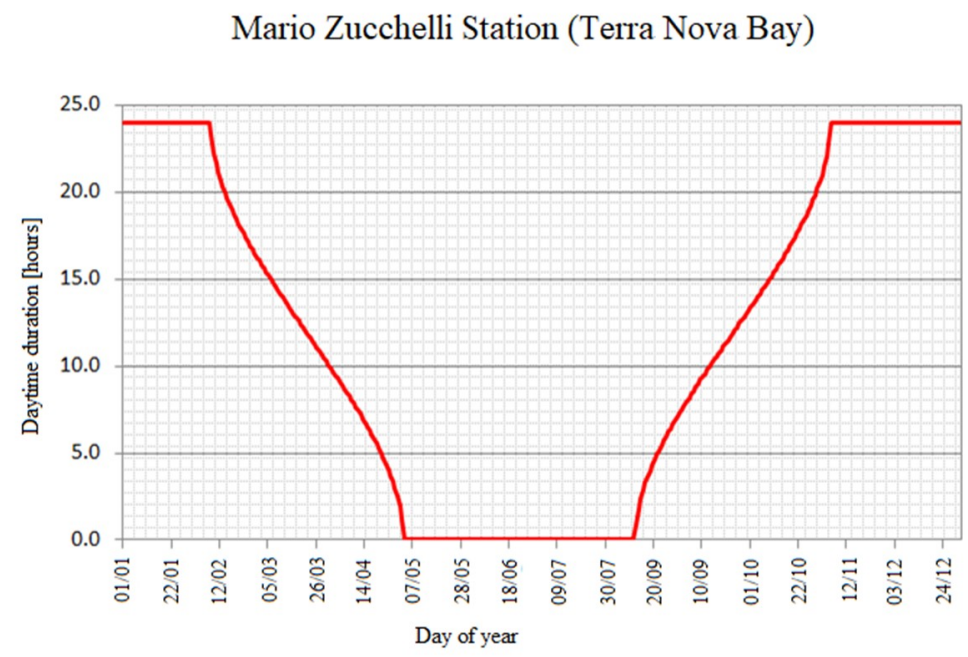

Figure 3. Daytime duration during the year at the MZS.

The three observed components by solar-metric instrument are linked by the following relationship:

$$
I=I_{\mathrm{bn}} \cos \theta_{\mathrm{z}}+I_{\mathrm{d}}
$$

where, $I$ is global horizontal irradiance, $I_{\mathrm{bn}}$ is the direct normal irradiance on the normal plane, $\theta_{\mathrm{z}}$ is the solar zenith angle and $I_{\mathrm{d}}$ the diffuse solar irradiance on the horizontal plane. The availability of the three observed solar components therefore makes it possible to validate the individual measurements. The solar zenith angle is the angle that the direction of the solar beams forms with the normal to the horizontal plane at a fixed location. The zenith angle is calculated according to the latitude and longitude, day number of the year and the time of day. The exact Sun position and the moment of acquisition are essential to Equation (1). The product of the Ibn with the cosine of the zenith angle is the direct irradiance referred not to the normal, but rather to the horizontal plane, for which the symbol $I_{\mathrm{b}}$ will be used from this point in the text:

$$
I_{\mathrm{b}}=I_{\mathrm{bn}} \cos \theta_{\mathrm{z}}
$$

The Equation (2), translated into the following relationship between the three irradiance components (GHI, DNI and Diff.HI), where all are referred to the horizontal arrangement is the sequent:

$$
I=I_{\mathrm{b}}+I_{\mathrm{d}}
$$

The dispersion graph covering the 65 days of the observed and calculated DNI values from Equation (3) is presented in Figure 4. Following the relationship in Equation (3), we could validate our observations and calculate one of the needed values if measurements for the other two are available. 


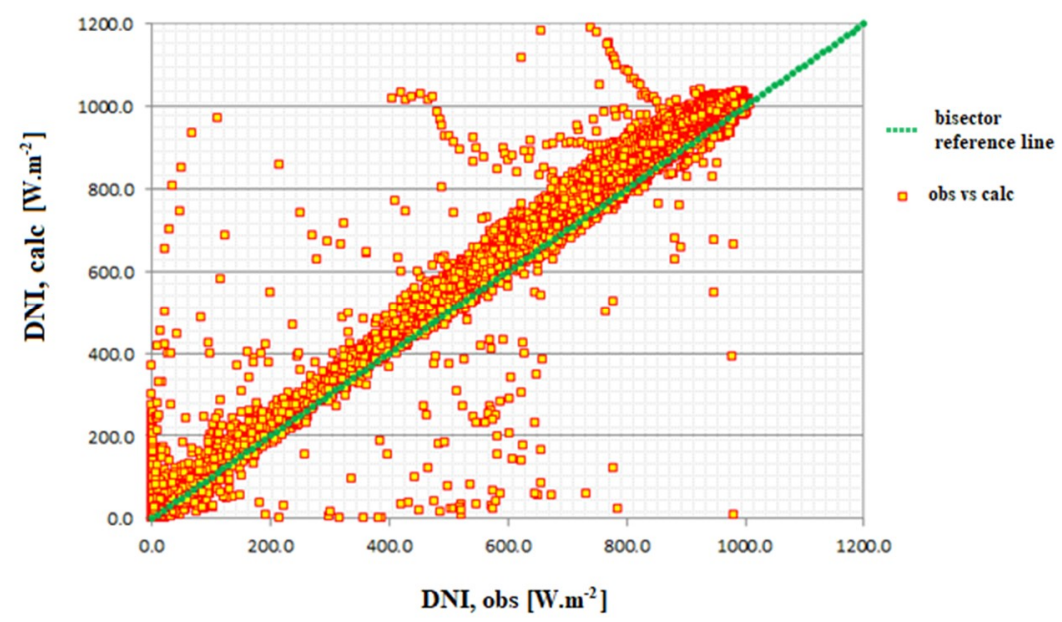

Figure 4. Dispersion graph of the hourly observed values (DNI, obs) vs the calculated DNI (DNI, calc) with bisector reference line (in green).

To begin with, all the observed data set must be validated. The good planning and execution of the observations certainly enables the elimination of the majority of systematic errors in the dataset. In the dataset, random errors inevitably occur, which are intimately connected to the observational process itself and can never be completely eliminated or prevented. The validation of the acquired dataset therefore has the purpose of identifying those values that are incorrect and excluding them from subsequent processing.

The validation tests that are used to check the accuracy of the measurement data in particular identifies inaccurate data, which do not satisfy the validation tests (Figure 5), and which are declared incorrect and excluded from processing. Nevertheless, exact data may be inaccurate where the measured data still can be affected by a lack of precision the magnitude of which depends on the (in)sensitivity of the instrument, random disturbances, and so on. In theory, indicated with $\Delta$, the allowable inaccuracy interval, a measure $m$ is acceptable if the value falls in the amplitude interval $\Delta$ centered on the true value $v$ :

$$
m \in v \pm \frac{\Delta}{2}
$$




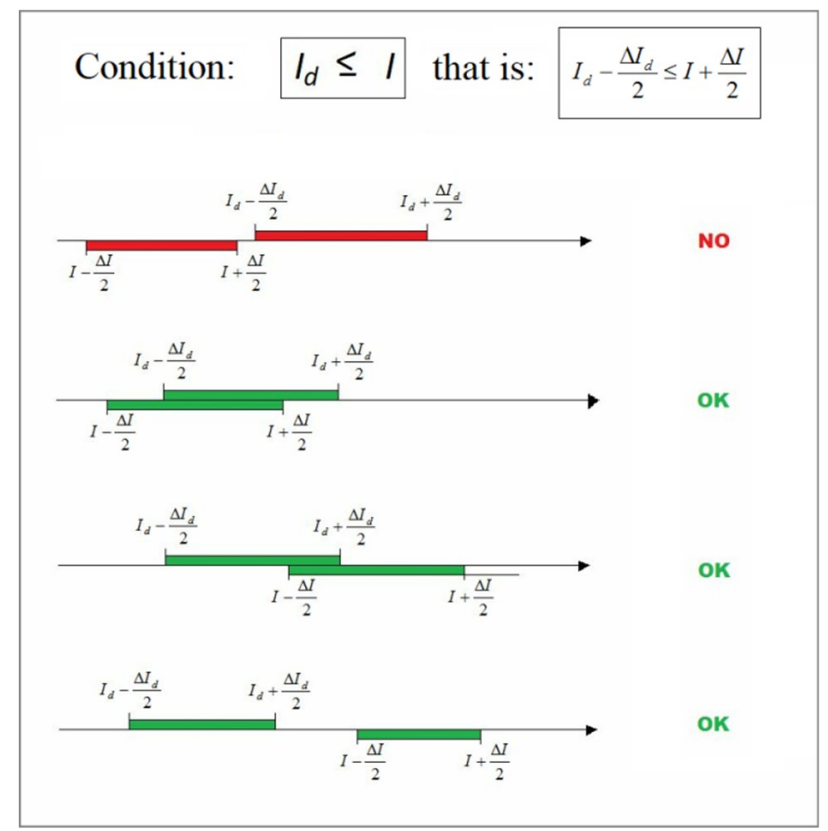

Figure 5. Validation of observation criteria.

However, since the true value is unknown, it will be a question of transforming the previous criteria, from time to time, in a suitable manner. Figure 5 graphically illustrates the criteria described above.

The intervals of imprecision for the horizontal global and diffuse irradiance are: $I \pm \Delta I / 2$ and $I_{\mathrm{d}} \pm$ $\Delta I_{\mathrm{d}} / 2$ respectively. With reference to the possible reciprocal positions, there are therefore four cases, of which only the first is incompatible with the criteria $I_{\mathrm{d}} \leq I$; the other three are collectively translated into the condition $I_{\mathrm{d}}-\frac{\Delta I_{\mathrm{d}}}{2} \leq I+\frac{\Delta I}{2}$.

In the night-time irradiance measurements, which theoretically should have zero values, they were found to have values almost always between the range $\pm 10 \mathrm{~W} \cdot \mathrm{m}^{-2}$. Therefore, it is reasonable to follow the inaccuracy interval as:

$$
\Delta I=\Delta I_{\mathrm{bn}}=\Delta I_{\mathrm{d}}=20 \mathrm{~W} / \mathrm{m}^{2}
$$

The same inaccuracy interval is followed for all three radiations components. Consequently, the summary of the validated data following the above criteria is (from now on) shown in Table 1:

Table 1. Summary of observed data.

\begin{tabular}{cc}
\hline Total Number of Records & 18,709 \\
(65 days) & \\
\hline $\begin{array}{c}\text { Number of "daily" records } \\
\text { Number of "daily" validated records }\end{array}$ & 18,545 \\
\hline
\end{tabular}

\subsection{Fine-Tuning Model}

The 10,641 triplet (GHI, DNI, Diff.HI) observed daily and validated records, related to a period of 65 consecutive days, cannot be considered sufficient to extrapolate an estimate of the radiation in Antarctica. Indeed, the period that extends for the entire calendar year of 365 days, cannot be considered sufficient for the multi-year characterization of Sun exposure on the ground in Antarctica. However, the observed period can provide an adequate sample if the purpose is to model the radiative phenomenon through the correlations between the three forms of radiation. In particular, the relationship between DNI and GHI is of particular interest in this study, where:

$$
\mathrm{DNI}=\text { function }(\mathrm{GHI})
$$


The quality of the relationship between the radiation components (3) lies in the fact that numerous expeditions in Antarctica have enabled the acquisition of a multi-decade historical series of hourly GHI, both at Eneide station and at the weather stations scattered around the Mario Zucchelli base. The availability of GHI data allows the derivation of the DNI through the previous relationship and consequently to fully characterize the area of the Mario Zucchelli base.

In the literature, numerous correlations between the irradiance components are attested, established in different geographical areas for different time intervals (hourly, daily and so on), as in References [7-11] and others. Historically, the most studied correlation is the dependence of the diffused component $k$ on the global atmospheric transmission coefficient $K_{\mathrm{T}}$ :

$$
k=f\left(K_{\mathrm{T}}\right)
$$

The global atmospheric transmission coefficient $\left(K_{\mathrm{T}}\right)$ is defined as the ratio between the global irradiance observed on the ground $(I)$ and the extraterrestrial irradiance $\left(I_{0}\right)$, both referred to the horizontal plane:

$$
K_{T}=\frac{I}{I_{0}}=\frac{\mathrm{GHI}}{\mathrm{EHI}}
$$

while the fraction of the horizontal diffused radiation $(k)$ with respect to the global irradiance is given by the ratio:

$$
k=\frac{I_{\mathrm{d}}}{I}=\frac{\mathrm{D}_{\mathrm{iff}} \mathrm{HI}}{\mathrm{GHI}}
$$

where $I_{\mathrm{d}}$ is diffuse horizontal irradiance (Diff.HI), Thus, the transmission coefficient for normal direct radiation $\left(K_{\mathrm{bn}}\right)$ is defined as:

$$
K_{\mathrm{bn}}=\frac{I_{\mathrm{bn}}}{I_{\mathrm{on}}}=\frac{\mathrm{DNI}}{\mathrm{ENI}}
$$

where $I_{\mathrm{on}}$ is the extraterrestrial normal irradiance. $K_{\mathrm{bn}}$ is primary relevant for the calculation of DNI, where could be derived from $K_{\mathrm{T}}$ and $k$ through the relationship:

$$
K_{\mathrm{bn}}=K_{\mathrm{T}}(1-k)
$$

An excellent correlation $k=f\left(K_{\mathrm{T}}\right)$ established by Reference [12] is as follows:

$$
k=\frac{1}{1+\mathrm{e}^{\alpha+\beta K_{\mathrm{T}}}}
$$

where, $\alpha$ and $\beta$ are the Boland-Ridley parameters defined for certain specific geographic locations [12]. Therefore, the relationship between DNI and GHI is derived from:

$$
\frac{K_{\mathrm{bn}}}{K_{\mathrm{T}}}=\frac{1}{1+\mathrm{e}^{-\alpha-\beta K_{\mathrm{T}}}}
$$

There are two non-negligible contraindications which need to be satisfied in order to obtain a direct correlation between the two parameter pairs; $\left(K_{\mathrm{T}}, k\right)$ and $\left(K_{\mathrm{T}}, K_{\mathrm{bn}}\right)$ :

(1) The dispersion graph of the parameters pair $\left(K_{\mathrm{T}}, k\right)$ in Figure 6 presents the excessive variability of the data around the hypothetical correlation curve. This phenomenon is inevitable considering that the radiative attenuation in the atmosphere depends on many other meteorological variables, which are all unpredictable and difficult to measure or estimate, such as: humidity, wind, temperature, aerosol content, and various others. Usually, the above-mentioned correlation is mostly studied through average hourly data, for which the variability is obviously less accentuated than the measures adopted in this study, carried out at a frequency of every $5 \mathrm{~min}$. 


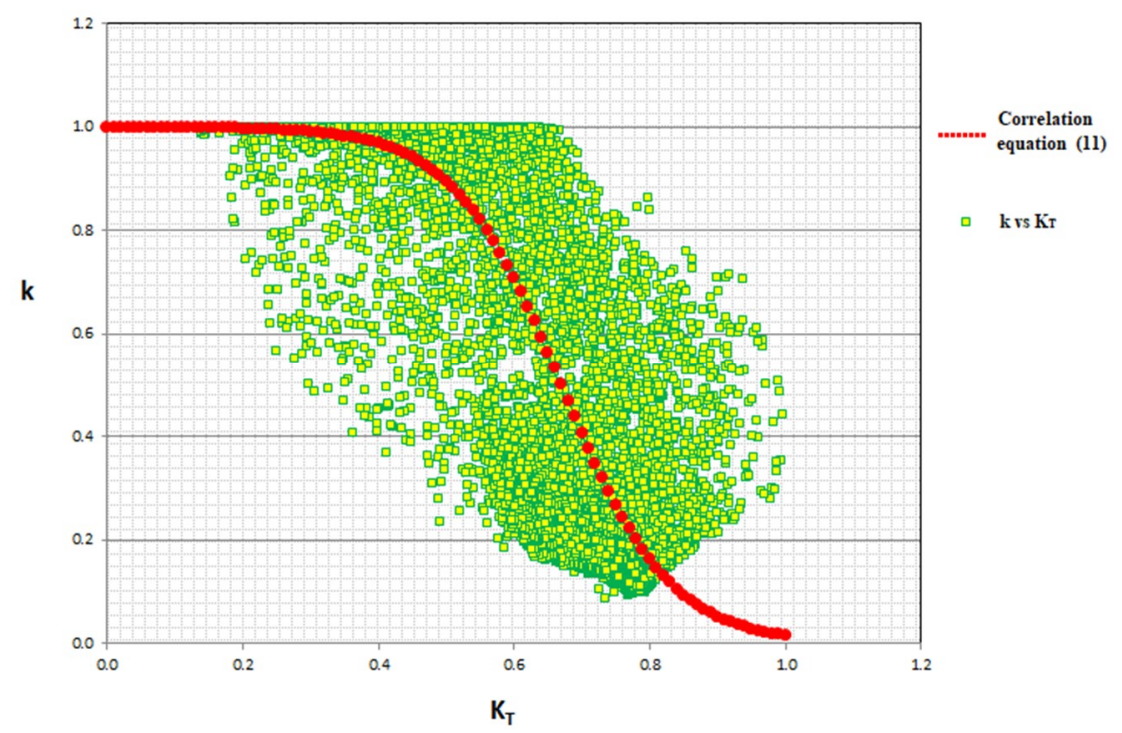

Figure 6. Dispersion graph of hourly parameter pairs of $\left(K_{\mathrm{T}}, k\right)$, where $K_{\mathrm{T}}$ is global transmission coefficient and $k$ is the fraction of the diffused radiation with respect to global radiation with their correlation Equation (11) proposed by Reference [12] (in red).

The same consideration also applies to the dispersion graph that considers the second pair of parameters $\left(K_{\mathrm{T}}, K_{\mathrm{bn}}\right)$ in Figure 7.

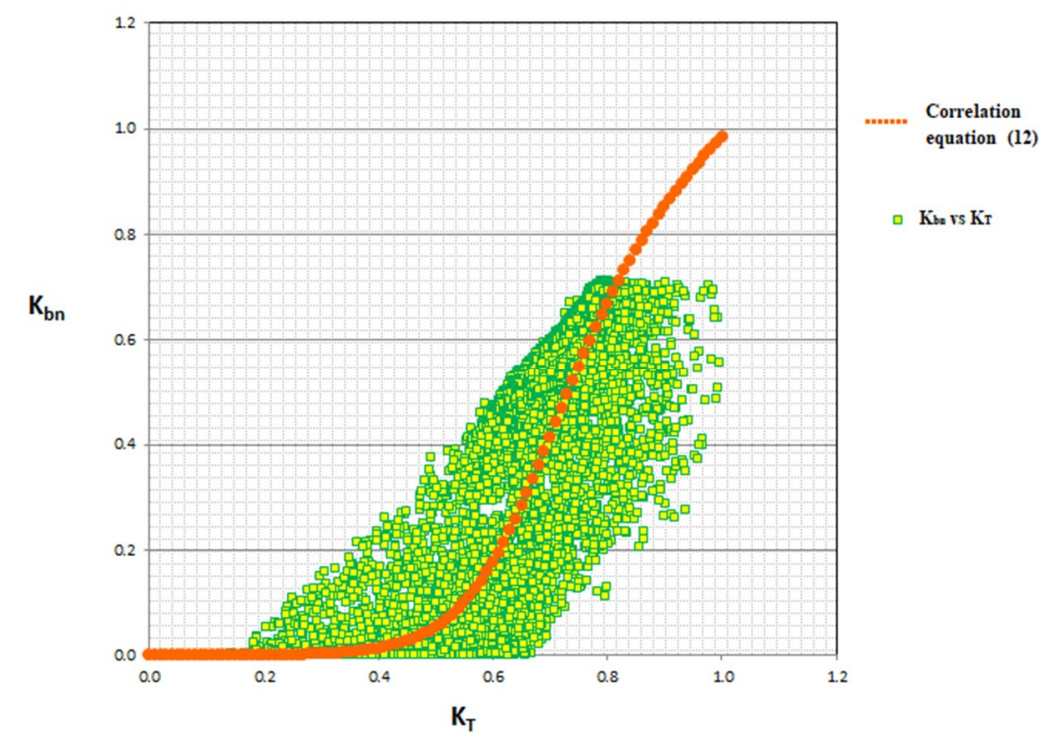

Figure 7. Dispersion graph of hourly parameter pairs $\left(K_{\mathrm{T}}, K_{\mathrm{bn}}\right)$, where $K_{\mathrm{T}}$ is global transmission coefficient and $K_{\mathrm{bn}}$ is the transmission coefficient for normal direct radiation with their correlation Equation (12) (in red).

(2) Usually the estimation of the regression parameters is carried out using the least squared method, which is computationally easy if the proposed correlation is linear. Therefore, until regression analysis can be applied to find the parameters $\alpha$ and $\beta$, it is necessary to transform Equation (11) in its linear expression, which contains the needed parameters that now can be estimated. Following the above, we obtain:

$$
\ln \left(\frac{1}{k}-1\right)=\alpha+\beta K_{T}
$$

The following parameters pair $\left(K_{\mathrm{bn}}, k\right)$ in Figure 8 better represent the measurements with the approximate fitting second order polynomial curve than the other two parameters pairs. On the 
graph we observe that the measurement points are gathered more strongly and continuously on the fitting curve.

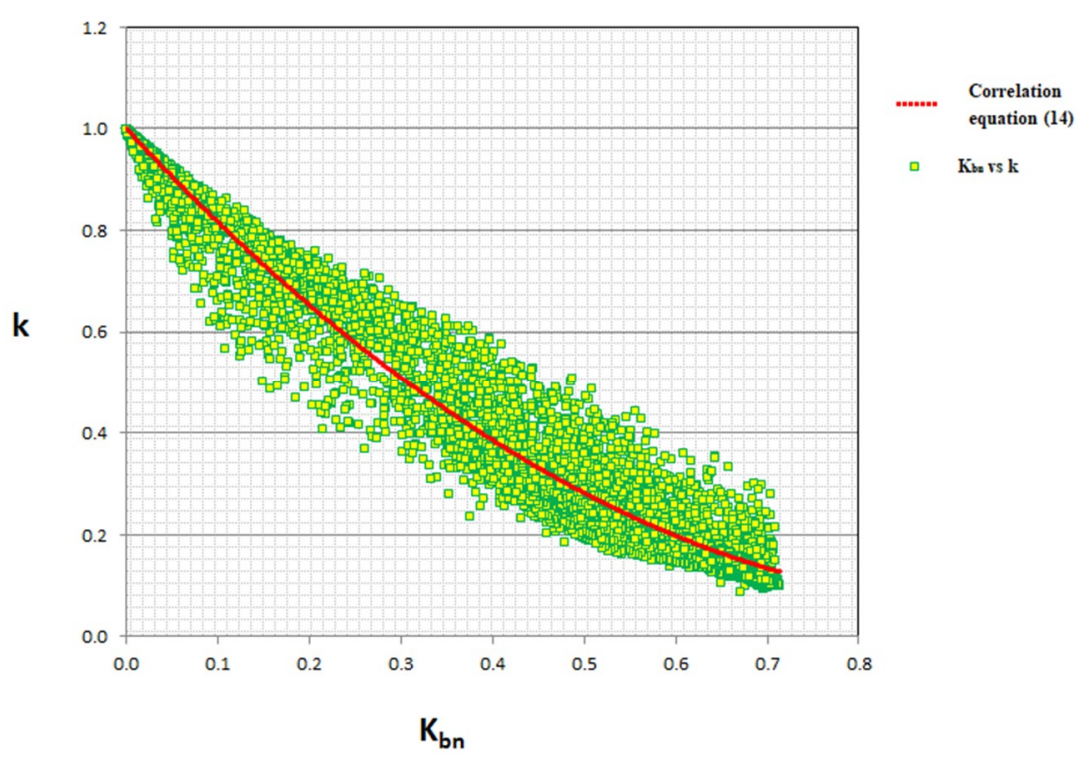

Figure 8. Dispersion graphs of hourly parameter pairs $\left(K_{\mathrm{bn}}, k\right)$, where and $K_{\mathrm{bn}}$ is the transmission coefficient for normal direct radiation and $k$ is the fraction of the diffused radiation with respect to global radiation with their correlation Equation (14) (in red).

In this case, the candidate second order polynomial is:

$$
k=a K_{\mathrm{bn}}^{2}+b K_{\mathrm{bn}}+c
$$

In conditions of zero direct radiation, $K_{\mathrm{bn}}=0$, and the global radiation becomes entirely composed of the diffused component; consequently the diffused fraction must be unitary, $k=1$. Therefore, in Equation (14) the constant $c$ is 1. When these assumptions are taken into account and the least squares method is applied, the regression on the parabola (14) produces the following estimates $\left(a=0.994, b=-1.93, R^{2}=0.98\right)$.

To interpret the parabolic correlation of Equation (14) in the Boland-Ridley formulas, it is necessary to report on a Cartesian reference of the abscissa $K_{\mathrm{T}}$ and the ordinate $k$, both the dependence $k=$ $f\left(K_{\mathrm{T}}\right)$ obtained by the polynomial expression (14) and also the dependence found in expression (11) of Boland-Ridley with different parameters pairs $(\alpha, \beta)$. Afterwards, we are able to estimate the final coefficients by regression. Proceeding in this way we obtain:

$$
\begin{aligned}
& \alpha=-9.18 \\
& \beta=14.28
\end{aligned}
$$

The two final coefficients (15) are estimated from Equation (11) considering the 65 days of observed data from the Antarctic region. Figures 9 and 10 show the final dispersion graphs between the three coefficients $\left(K_{\mathrm{T}} ; k, K_{\mathrm{bn}}\right)$ and the estimated interpolation curves. The Boland-Ridley model uses the $\alpha$ and $\beta$ coefficients for the European (blue) and Australian (violet) regions [13], while the model developed in this study uses the calculated coefficients (15) for the Antarctic region (ENEA). 


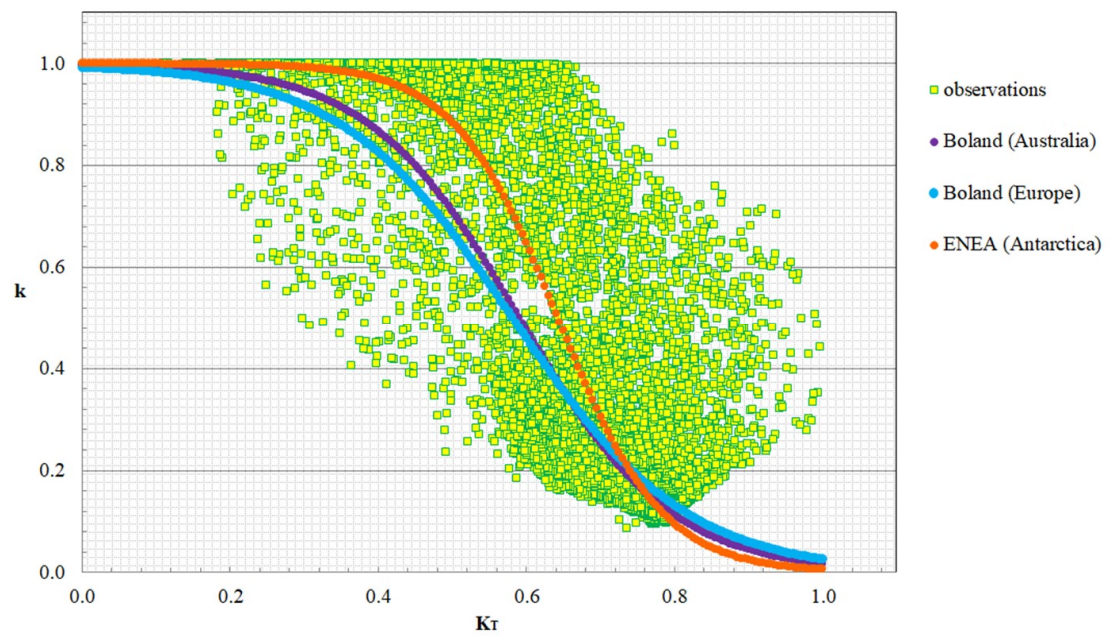

Figure 9. Dispersion graph of parameter pairs $\left(K_{\mathrm{T}}, k\right)$ obtained from long GHI dataset using the Boland-Ridley model for the European (blue) and Australian (violet) regions [13] and the ENEA model for the Antarctic region (red).

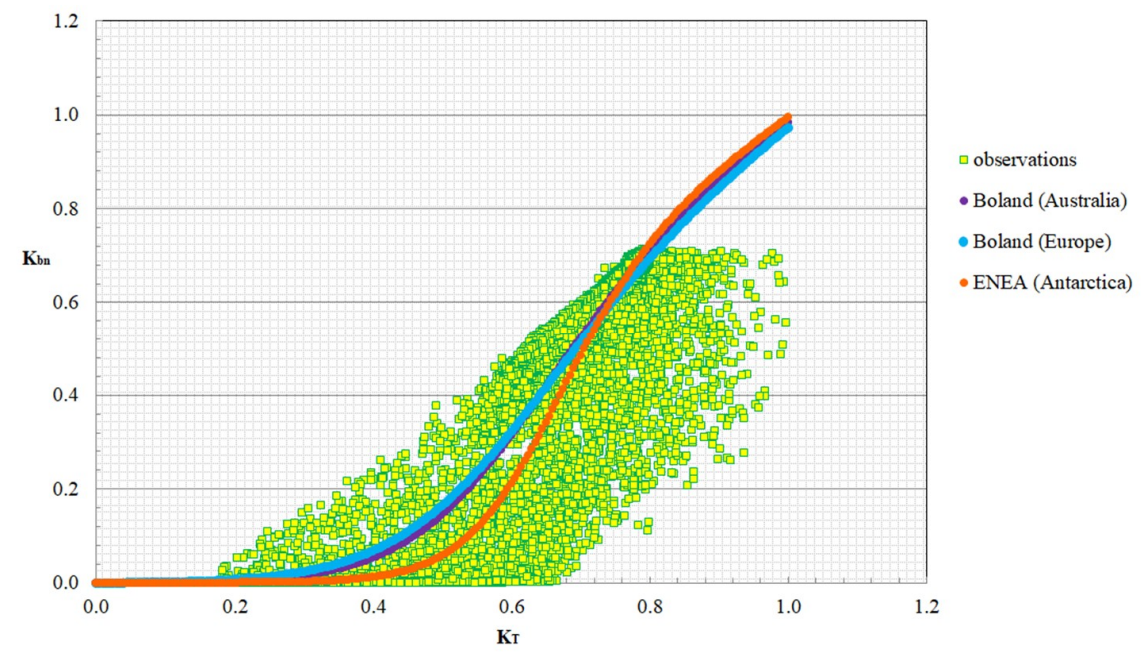

Figure 10. Dispersion graph of parameter pairs $\left(K_{\mathrm{T}}, K_{\mathrm{bn}}\right)$ obtained from long GHI dataset using the Boland-Ridley model for the European (blue) and Australian (violet) regions [13] and the ENEA model for the Antarctic region (red).

\subsection{Model Validation}

The models, in general, when developed according to the acquired observational data set, need to be compared with the corresponding estimates, and whether the deviation magnitudes do not compromise the quality of the proposed model needs to be evaluated. In order to quantify the quality of the proposed model, some statistical indicators are useful. The first of these indicators, called the Mean Bias Error (MBE), is simply the difference between the mean estimate values and the observation values. In our case, the calculated value is:

$$
\mathrm{MBE}=\frac{1}{N} \sum_{\mathrm{i}=1}^{N}\left(I_{\mathrm{bn}, \mathrm{i}, \mathrm{c}}-I_{\mathrm{bn}, \mathrm{i}, \mathrm{o}}\right)=14.6 \frac{\mathrm{W}}{\mathrm{m}^{2}}
$$

In the above expression, $N=10,641$, it is the total number of observation pairs in the data; the subscript " $\mathrm{i}$ " refers to the $\mathrm{i}$-th pair, while " $\mathrm{o}$ " and " $\mathrm{c}$ " refer to the observations and calculated values, respectively. The estimates are calculated using Equation (12) with the values given by Equation (15). The low value of the MBE means that the measurements and estimates are offset on the average value. 
Even though, a low (or, at least, zero) MBE value does not exclude the possibility that there are some significant gaps between the measurements and the estimates, even potentially in a non-negligible number. In order to underline the variance index that takes the above fact into account, it is useful to use the Mean Absolute Error (MAE), which in our case gives:

$$
\mathrm{MAE}=\frac{1}{N} \sum_{\mathrm{i}=1}^{N}\left|I_{\mathrm{bn}, \mathrm{i}, \mathrm{c}}-I_{\mathrm{bn}, \mathrm{i}, \mathrm{o}}\right|=117.75 \frac{\mathrm{W}}{\mathrm{m}^{2}}
$$

or, in relative terms:

$$
\frac{\mathrm{MAE}}{\overline{\mathrm{I}}_{\mathrm{bn}, \mathrm{o}}}=0.227=22.7 \%
$$

where, $\overline{\mathrm{I}}_{\mathrm{bn}, \mathrm{o}}$ is indicated as the average of the DNI measurements, which results in:

$$
\overline{\mathrm{I}}_{\mathrm{bn}, \mathrm{o}}=\frac{1}{N} \sum_{\mathrm{i}=1}^{N} I_{\mathrm{bn}, \mathrm{i}, \mathrm{o}}=516.7 \frac{\mathrm{W}}{\mathrm{m}^{2}}
$$

Another widely used quality deviation index is the Root Mean Squared Error (RMSE) which, compared to the previous evaluated MAE, considers the squares of the discard rather than the absolute values, in order to attribute a greater weight to higher deviations in the summation, such as:

$$
\text { RMSE }=\sqrt{\frac{1}{N} \sum_{\mathrm{i}=\mathrm{i}}^{N}\left(I_{\mathrm{bn}, \mathrm{i}, \mathrm{c}}-I_{\mathrm{bn}, \mathrm{i}, \mathrm{o}}\right)^{2}}=171.8 \frac{\mathrm{W}}{\mathrm{m}^{2}}
$$

The final quality index considered here can be obtained by comparing the average DNI values of all the measurements and the corresponding estimated values. Since the average value of the DNI estimate is calculated as:

$$
\overline{\mathrm{I}}_{\mathrm{bn}, \mathrm{c}}=\frac{1}{N} \sum_{\mathrm{i}=1}^{N} I_{\mathrm{bn}, \mathrm{i}, \mathrm{c}}=531.4 \frac{\mathrm{W}}{\mathrm{m}^{2}}
$$

we finally get:

$$
\frac{\overline{\mathrm{I}}_{\mathrm{bn}, \mathrm{c}}-\overline{\mathrm{I}}_{\mathrm{bn}, \mathrm{o}}}{\overline{\mathrm{I}}_{\mathrm{bn}, \mathrm{o}}}=\frac{531.4 \frac{\mathrm{W}}{\mathrm{m}^{2}}-516.7 \frac{\mathrm{W}}{\mathrm{m}^{2}}}{516.7 \frac{\mathrm{W}}{\mathrm{m}^{2}}}=\frac{14.7}{516.7}=+0.028=+2.8 \%
$$

The summary of statistical measures of presented model is compared with Boland-Ridley coefficients for Australia and Europe taken from Reference [13] are presented in Table 2. Within the new calculated $\alpha$ and $\beta$ coefficients for Antarctic region from observed data we reduced the model error from $12.9 \%$ considering the known coefficients for Australia to $2.8 \%$.

Table 2. Model comparators with different regional Boland-Ridley coefficients.

\begin{tabular}{cccc}
\hline Statistics & Australia & Europe & Antarctica (ENEA) \\
\hline $\mathrm{MBE}\left[\mathrm{W} / \mathrm{m}^{2}\right]$ & 66.57 & 73.64 & 14.6 \\
$\mathrm{MAE}\left[\mathrm{W} / \mathrm{m}^{2}\right]$ & 168.36 & 170.86 & 117.75 \\
{$\left[\mathrm{~W} / \mathrm{m}^{2}\right]$} & 583.30 & 590.40 & 531.40 \\
Error $[\%]$ & 12.9 & 14.3 & 2.8 \\
\hline
\end{tabular}

The values of the reported quality indicators are affected by the complexity of the phenomenology of solar radiation and its components that reach the ground. They depend on numerous meteorological factors which are contingent and difficult to establish for the purpose of fine-tuning models. In this study, we tried to develop a fine-tuning model which is established on the basis of high acquisition 
frequency data (every $5 \mathrm{~min}$ ). Usually the models are developed with reference to hourly data, in which the variability inherent in the phenomenon is established thanks to the much longer measurement intervals that are considered. Nevertheless, the values of the above obtained quality indices are in line with similar studies based on hourly data [7,10-12].

\section{Results}

\subsection{Analysis of the Estimated Monthly and Annual DNI from GHI}

Next, having validated our fine-tuned model based on 65 consecutive observations of all three radiations components, the following step is to extrapolate the presented model onto the entire observed GHI dataset at and near MZS. The Eneide observation site hosts a control unit that has acquired all the GHI data from 1987. In this study, the GHI observations from Eneide station are used to construct the time series of the DNI at the same location using the estimation model described in Section 2.4. To this purpose, the time series covered by the interval from 1999 until 2013 was considered, with a series of 15 years of data.

This long dataset includes GHI hourly data observations, where the corresponding hourly value of the DNI is estimated using the following algorithm:

$$
\begin{aligned}
& \text { Input : GHI } \\
& K_{\mathrm{T}}=\frac{\mathrm{GHI}}{\mathrm{EHI}}=\frac{\mathrm{GHI}}{\mathrm{ENI} \cdot \cos \theta_{\mathrm{z}}} \\
& \text { Correlation : } K_{\mathrm{bn}}=\frac{K_{\mathrm{T}}}{1+\mathrm{e}^{-\alpha-\beta K_{\mathrm{T}}}} \text { [model Boland - Ridley - ENEA/Antarctica] } \\
& \text { DNI }=K_{\mathrm{bn}} \cdot \mathrm{ENI}
\end{aligned}
$$

In the above formulas we need certain already known quantities: ENI is the normal extra-atmospheric irradiance, $\mathrm{EHI}$ is the horizontal extraterrestrial irradiance $\left(\mathrm{EHI}=\mathrm{ENI} \cdot \cos \theta_{\mathrm{z}}\right)$, and, finally, $\alpha=-9.18$ and $\beta=14.28$ (15) the Boland-Ridley coefficients estimated by ENEA for the Antarctica.

The final summary of the average daily monthly and annual daily DNI at Eneide station, relative to the 1998-2013 periods, is shown in Table 3 and the annual trends are plotted in Figure 11. The presented data show that the validated observations of GHI and estimated DNI start from November 1999. In the last row of Table 3, mean monthly values for all years are calculated, except 1998 and 1999 where annual trend was observed as unlikely and 2002 and 2008, where the data was incomplete. The results show the annual DNI at Eneide varied between a minimum value of $1794 \mathrm{kWh} \cdot \mathrm{m}^{-2}$ year in 2005 and a maximum of $2223 \mathrm{kWh} \cdot \mathrm{m}^{-2}$ in 2013, with an average of $2014 \mathrm{kWh} \cdot \mathrm{m}^{-2}$.

Table 3. Daily monthly mean and annual mean values of DNI $\left[\mathrm{kWh} \cdot \mathrm{m}^{-2}\right]$ estimated from GHI at Eneide (MZS) meteorological station.

\begin{tabular}{cccccccccccccc}
\hline Year & Jan. & Feb. & Mar. & Apr. & May & June & July & Aug. & Sept. & Oct. & Nov. & Dec. & Year \\
\hline 1998 & 4.162 & 1.812 & 0.608 & 0.082 & 0.001 & 0 & 0 & 0.088 & 0.885 & 2.239 & 5.066 & 5.101 & 609.9 \\
1999 & 3.517 & 1.628 & 0.522 & 0.122 & 0.001 & 0 & 0 & 0.269 & 1.011 & 2.558 & 9.082 & 16.660 & 1081.4 \\
2000 & 14.521 & 8.264 & 4.375 & 1.145 & 0.003 & 0 & 0 & 0.355 & 4.109 & 7.746 & 9.778 & 13.129 & 1934.6 \\
2001 & 11.306 & 10.745 & 7.074 & 1.252 & 0.003 & 0 & 0 & 0.418 & 5.740 & 10.520 & 11.330 & 14.670 & 2214.2 \\
2002 & 9.691 & 9.412 & 4.187 & 1.723 & 0.001 & 0 & - & - & - & - & 12.988 & - & - \\
2003 & 13.296 & 11.454 & 5.282 & 1.822 & 0.007 & 0 & 0 & 0.260 & 0.569 & 5.292 & 8.793 & 15.291 & 1878.5 \\
2004 & 13.390 & 6.611 & 4.852 & 1.235 & 0.000 & 0 & 0 & 0.366 & 3.856 & 9.059 & 12.150 & 16.076 & 2065.0 \\
2005 & 9.632 & 7.952 & 4.620 & 1.836 & 0.001 & 0 & 0 & 0.338 & 4.425 & 6.732 & 14.041 & 9.731 & 1794.4 \\
2006 & 10.738 & 7.896 & 5.860 & 2.016 & 0.006 & 0 & 0 & 0.300 & 1.719 & 7.801 & 12.424 & 16.346 & 1978.4 \\
2007 & 10.724 & 7.751 & 4.443 & 1.213 & 0.005 & 0 & 0 & 0.057 & 4.588 & 7.071 & 14.229 & 14.574 & 1968.8 \\
2008 & 10.627 & 6.239 & - & - & - & - & - & - & - & - & 13.005 & 14.789 \\
2009 & 12.411 & 5.533 & 5.406 & 1.415 & 0.007 & 0 & 0 & 0.542 & 6.165 & 8.358 & 11.122 & 11.649 & 1905.5 \\
2010 & 10.611 & 6.838 & 3.599 & 1.757 & 0.006 & 0 & 0 & 0.207 & 3.463 & 9.917 & 15.768 & 14.453 & 2023.7 \\
2011 & 13.393 & 6.379 & 4.577 & 1.167 & 0.005 & 0 & 0 & 0.425 & 3.225 & 8.564 & 14.055 & 17.301 & 2104.2 \\
2012 & 13.216 & 9.968 & 4.776 & 1.505 & 0.002 & 0 & 0 & 0.324 & 3.380 & 9.241 & 14.702 & 11.463 & 2076.4 \\
2013 & 14.494 & 8.162 & 4.141 & 0.957 & 0.001 & 0 & 0 & 0.226 & 4.523 & 8.402 & 15.818 & 16.491 & 2223.9 \\
mean & 12.311 & 8.129 & 4.917 & 1.443 & 0.004 & 0 & 0 & 0.318 & 3.814 & 8.225 & 12.561 & 14.449 & 2014.0 \\
\hline
\end{tabular}




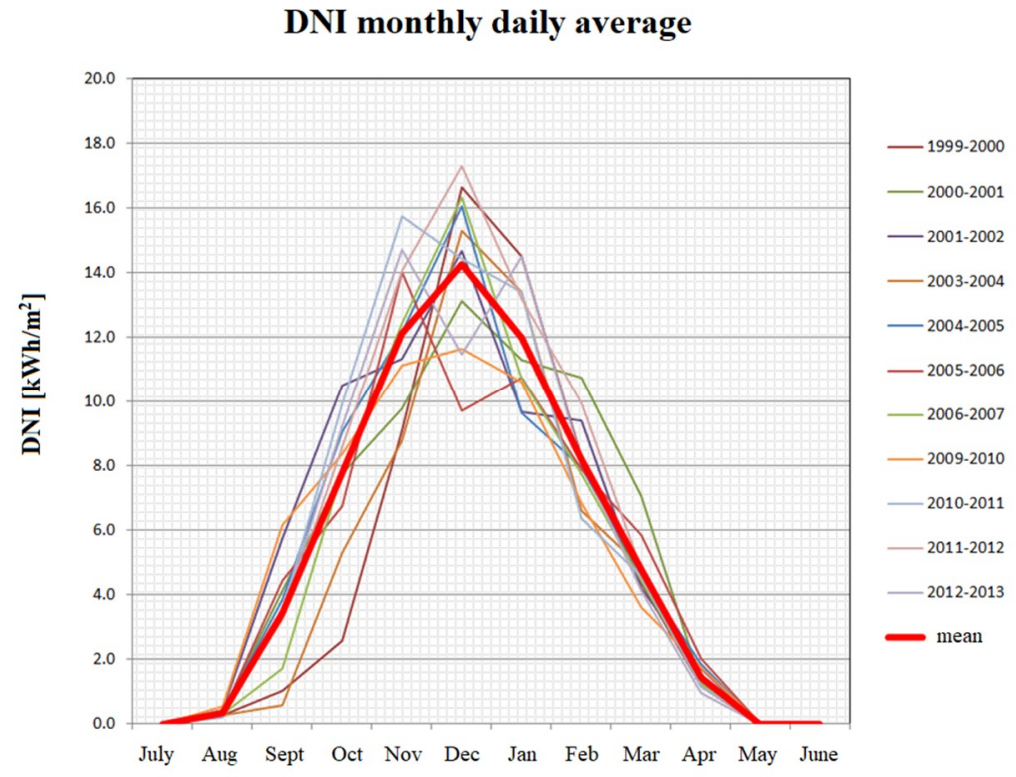

Figure 11. Annual evolution of the daily average monthly DNI values and mean annual evolution (in red) at Eneide (MZS) station.

In Figure 11, the annual and mean trends of average monthly DNI values at Eneide station are presented, with respect to the Antarctic seasons. On the horizontal axis, intervals equal to one year starting from July and ending in June of the following calendar year are considered, in order to reproduce the familiar "bell" trend of the radiation over the year observed at others latitude. In Figure 11, we have omitted those annual period with missing or invalid data (2002-2003 and 2008-2009).

\subsection{Effective Case Study Analysis}

We propose a parabolic dish as a CS technology to generate electricity at Mario Zuccheli base. CS technology uses only the direct solar component. Parabolic dish technology is composed of the following units: a parabolic dish, a receiver compressor, a turbine and a recuperator (Figure 12). The electric power generators integrated into the dish-MGT (Micro Gas Turbine) systems are mostly based on the simple recuperated Joule-Brayton cycle.

The parabolic dish unit (Figure 12a) is made from a high efficiency mirror created to concentrate the direct Sun's beam onto a receiver unit mounted on its focal point, where the solar energy is converted into heat. The heat is used to create pressurized steam inside the compressor unit from the ambient air. The air exiting the receiver flows into the turbine unit where it is expanded and then sent to the hot end of the recuperator unit. Inside the recuperator the hot air is cooled down by the compressor delivery air before being released into the atmosphere. When the available solar radiation exceeds the maximum turbine value, a fraction of the total mass flow through the engine bypasses both sides of the recuperator, in order to reduce the inlet temperature to the solar receiver and avoid overheating of the system [14]. The conceptual scheme and flow diagram of the MGT process is presented in Figure 12a. The parabolic dish external diameter is considered to be $11.7 \mathrm{~m}$, with an effective aperture area of $96.1 \mathrm{~m}^{2}$ and a focus quote of $7 \mathrm{~m}$, while the receiver window diameter is $190 \mathrm{~mm}$. 


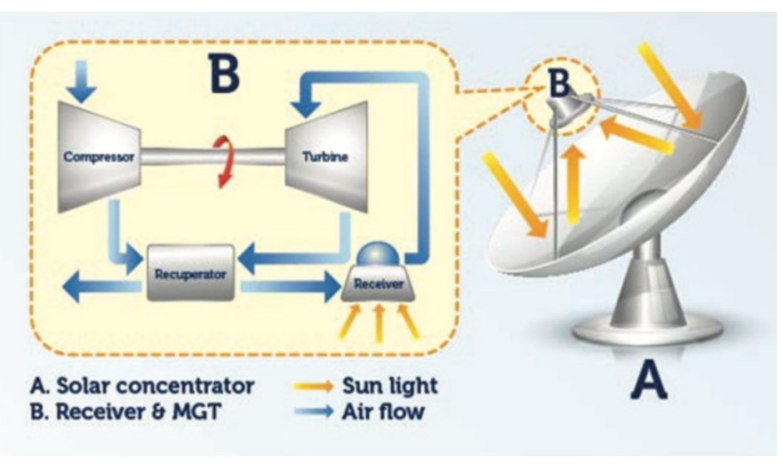

(a)

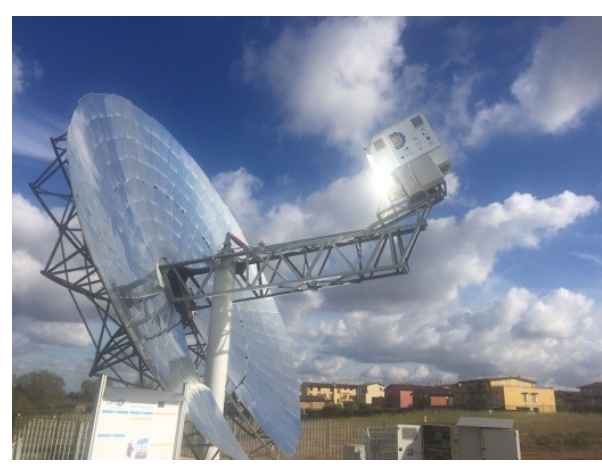

(b)

Figure 12. Parabolic dish, (a) Conceptual scheme (A-dish solar concentrator, B-receiver and micro gas turbine) and (b) parabolic dish at ENEA [14].

In Antarctica, the direct solar radiative potential consistent in estimated DNI annual average from 2000 until 2013 year is $2014 \mathrm{kWh} \cdot \mathrm{m}^{-2}$ per year (Table 4). In order to make a comparison to the DNI values in other parts of the world, for example, in the southern part of Italy, the potential annual average in DNI is $1850 \mathrm{kWh} \cdot \mathrm{m}^{-2}$ per year. The daily DNI value in Antarctica is $16 \mathrm{kWh} \cdot \mathrm{m}^{-2}$, while in Italy the DNI daily value reaches $10 \mathrm{kWh} \cdot \mathrm{m}^{-2}[4,5]$.

Table 4. Performance of parabolic dish, annually and in the summer season.

\begin{tabular}{ccc}
\hline $\begin{array}{c}\text { Location and } \\
\text { Time Frame }\end{array}$ & $\begin{array}{c}\text { Mario Zucchelli Station } \\
\text { (Entire Year) }\end{array}$ & $\begin{array}{c}\text { Mario Zucchelli Station } \\
\text { (Austral Summer) }\end{array}$ \\
\hline DNI average $\left[\mathrm{kWh} \cdot \mathrm{m}^{-2}\right]$ & 2014.0 & 1795.0 \\
$E_{\mathrm{sol}}[\mathrm{kWh}]$ & $193,545.5$ & $172,499.5$ \\
$Q_{\mathrm{sol}}[\mathrm{kWh}]$ & $176,126.3$ & $156,974.5$ \\
$E_{\mathrm{el}}[\mathrm{kWh}]$ & $36,985.5$ & $32,964.6$ \\
\hline
\end{tabular}

The parabolic dish design specifications, such as the reflective efficiencies of the collector factor $(90 \%)$ and the global efficiency in produced electricity $(21 \%)$ are taken from Reference [15]. Further on, when we evaluated the DNI potential at the desired location and we know the specific parabolic dish characteristics we are able to evaluate the annual and summer electricity production $\left(E_{\mathrm{el}}\right)$ of our system. The available solar energy input $\left(E_{\mathrm{sol}}\right)$ depends on the effective aperture area of the parabolic dish and the DNI while the solar energy actually harvested by the system $\left(Q_{\text {sol }}\right)$ depends on the reflective efficiencies of the parabolic dish collector factor.

The values in Table 4 give us a theoretical ratio that the electricity produced only in the summer is $89 \%$ of the electricity produced throughout the entire year. Based on these values, it seems convenient to envisage a CS power plant for the supply of energy needs for the Mario Zucchelli base.

\section{Discussion}

In this paper, important results for the DNI estimation over the Antarctic region are presented. The valuable observations in all three components of solar radiation were conducted during the XXVIII scientific expedition carried out in the austral summer of 2012/2013 at the Mario Zucchelli base. Those observations made it possible to find the fine-tuning model between direct and global irradiance, which was then extrapolated to the entire observation dataset in this area.

The fine-tuning model offered the possibility for a feasibility study and evaluation of a possible CS plant in this location. Within presented fine-tuned model we reduced the error in calculated DNI from observed GHI values in Antarctica from 12.9\% considering the known Boland-Ridley coefficients for Australia to $2.8 \%$. The DNI levels estimated for the Antarctica region suggest a positive outcome from designing and installing a renewable power plant that uses CS technology at the Mario Zucchelli 
Station. This type of power plant is studied at ENEA. This type of renewable power plant with environmentally friendly characteristics of transfer fluid is suitable for use in Antarctica.

We considered Reference [16], where the multi-predictor approach is used in diffraction model. The multi-predictor approach was applied to the dataset where no significant improvements are found and where calculation error has not decreased below presented $2.8 \%$. In this sense, the usage of two parameters model is correct where presented calculation error is included in observational error. The usage of simpler model with two predictors was found to be more efficient with respect to multi-predictor model in this specific region where ground albedo have high values due to present snow cover for entire year. Until there is no unique and precise diffraction model for all global locations, with this work we added an important contribution with two parameters in the diffraction model for the Antarctic region.

\section{Conclusions}

This power plant can contribute to the production of electricity that could satisfy in summer months the considerable energy required for the operation of the permanent research station. We found that $89 \%$ of the total electricity is produced in the summer, which could contribute to renewable energy production at the Mario Zucchelli base in the period when the base is crowded with scientific staff. A good relationship between DNI and GHI on a horizontal plane is of fundamental importance in estimation of global irradiance on any oriented tilted surface for a photovoltaic application. The presented technology could contribute to renewable energy production (for example, a mini wind turbine and new photovoltaic panels) installed by ENEA in this area [17].

Among the CS technologies, the one with a punctual parabolic concentration has the characteristics that lend themselves well to being used in Antarctica in two specific ways: first, they use a non-toxic gas as a heat transfer fluid, and second, this technology is (relatively) compact and could be transferred directly by transportation ship. Finally, this technology is modular and can be expanded according to power needs.

Author Contributions: All authors contributed in writing and correcting the paper. F.S. conceived the idea. G.N. and L.D.S. realized the installation and observations with solar-metric station in Antarctica, where P.G. and L.D.S. are responsible for Italian observational AWS network in Antarctica. I.B., F.S. and G.C. implemented the models and realized the numerical calculations, analyzed the experimental and numerical results. The paper was written by I.B., F.S., and G.C. and revised by all authors.

Funding: Research was funded by PNRA project in 2012/2013. The funders had no role in the design of the study; in the collection, analyses, or interpretation of data; in the writing of the manuscript, and in the decision to publish the results.

Acknowledgments: We would like to thank all our colleagues from the XXVIII scientific expedition inside the PNRA project in 2012/2013, who made this work possible.

Conflicts of Interest: The authors declare no conflicts of interest. 


\section{Nomenclatures}

\begin{tabular}{|c|c|}
\hline PNRA & National Plan of Research in Antarctica \\
\hline GHI & Global Horizontal Irradiance, I $\left[\mathrm{W} \cdot \mathrm{m}^{-2}\right]$ \\
\hline DNI & Direct Normal Irradiance on horizontal plane, $\mathrm{Ib}\left[\mathrm{W} \cdot \mathrm{m}^{-2}\right]$ \\
\hline Diff.HI & Diffuse Irradiance on horizontal plane, Id $\left[\mathrm{W} \cdot \mathrm{m}^{-2}\right]$ \\
\hline AWS & Automatic Weather Station \\
\hline MSD & mean standard deviation \\
\hline RMSE & Root Mean Squared Error \\
\hline MZS & Mario Zucchelli permanent station \\
\hline DC & Dome C, Concordia permanent station \\
\hline CSP & Concentrated Solar Power \\
\hline ENI & Extraterrestrial Irradiance on normal plane, Ion $\left[\mathrm{W} \cdot \mathrm{m}^{-2}\right]$ \\
\hline EHI & Extraterrestrial Irradiance on horizontal plane, Io $\left[\mathrm{W} \cdot \mathrm{m}^{-2}\right]$ \\
\hline MBE & Mean Bias Error \\
\hline MAE & Mean Absolute Error \\
\hline RMSE & Root Mean Squared Error \\
\hline ITASE & International Trans Antarctic Scientific Expedition \\
\hline MGT & Micro Gas Turbine \\
\hline ENEA & $\begin{array}{l}\text { Italian National Agency for New Technologies, Energy and Sustainable Economic } \\
\text { Development }\end{array}$ \\
\hline DTE-STSN & $\begin{array}{l}\text { ENEA-Department Energetic Technology, Division Solar Thermic, Thermodynamic, } \\
\text { and Smart Network }\end{array}$ \\
\hline SSPT-PROTER & ENEA-Divisione Protezione e valorizzazione del territorio e del capitale natural \\
\hline$\theta_{\mathrm{z}}$ & Solar zenith angle $[\mathrm{rad}],\left[^{\circ}\right]$ \\
\hline$I_{\mathrm{bn}}$ & Direct normal irradiance on normal plane, $\left[\mathrm{W} \cdot \mathrm{m}^{-2}\right]$ \\
\hline$K_{\mathrm{T}}$ & Global atmospheric transmission coefficient at specific location \\
\hline$K_{\mathrm{bn}}$ & Transmission coefficient for normal direct radiation \\
\hline $\mathrm{k}$ & $\begin{array}{l}\text { The fraction of the diffused radiation with respect to global radiation (refer to the } \\
\text { horizontal plane) }\end{array}$ \\
\hline$\alpha, \beta$ & Boland-Ridley parameters \\
\hline$E_{\mathrm{el}}$ & parabolic dish electricity production \\
\hline$E_{\text {sol }}$ & Available solar energy input \\
\hline$Q_{\text {sol }}$ & Solar energy actually harvested by the system \\
\hline
\end{tabular}

\section{References}

1. Antarctic Meteo-Climatological Observatory. Available online: http://www.climantartide.it (accessed on 27 June 2019).

2. Antarctic Automatic Weather Stations Project. Available online: https://amrc.ssec.wisc.edu (accessed on 27 June 2019).

3. National Program of Research in Antarctica. Available online: http://www.pnra.it (accessed on 27 June 2019).

4. Fontanella, A.; Crescenzi, T.; Di Mario, F.; Fabrizi, F.; Mazzei, D. Quadreno Solare Termodinamico; ENEA: Rome, Italy, 2011.

5. Fontanella, A. Solare termico a concentrazione. In Le Tecnologie Delle Fonti Rinnovabili Di Energia; Putti, P.M., Bramanti, O., Eds.; Gruppo 24ore: Milan, Italy, 2012; ISBN 978-88-324-8314-7.

6. Spencer, J.W. Fourier series representation of position of the Sun. Search 1971, 2, 162-172.

7. Erbs, D.G.; Klein, S.A.; Duffie, J.A. Estimation of the diffuse radiation fraction for hourly, daily and monthly-average global radiation. Sol. Energy 1982, 28, 293-302. [CrossRef]

8. Liu, B.; Jordan, R. The interrelationship and characteristic distribution of direct, diffuse and total solar radiation. Sol. Energy 1960, 4, 1-19. [CrossRef]

9. Collares-Pereira, M.; Rabl, A. The average distribution of solar radiation-correlation between diffuse and hemispherical and between daily and hourly insolation values. Sol. Energy 1979, 22, 155-164. [CrossRef]

10. Iqbal, M. An Introduction to Solar Radiation, 1st ed; Academic Press: Toronto, ON, Canada, 1983; p. 390, ISBN 0-12-373750-8. 
11. Reindl, D.T.; Beckman, W.A.; Duffie, J.A. Diffuse fraction correlations. Sol. Energy 1990, 45, 1-7. [CrossRef]

12. Boland, J.; Ridley, B. Models of diffuse solar fraction. In Modeling Solar Radiation at the Earth's Surface; Badescu, V., Ed.; Springer: Berlin, Germany, 2008; ISBN 978-3-540-77454-9.

13. Boland, J.; Ridley, B.; Brown, B. Models of diffuse solar radiation. Renew. Energy 2008, 33, 575-584. [CrossRef]

14. Lanchi, M.; Montecchi, M.; Crescenzi, T.; Mele, D.; Miliozzi, A.; Russo, V.; Mazzei, D.; Misceo, M.; Falchetta, M.; Mancini, R. Investigation into the coupling of micro gas turbines with CSP technology: OMSoP project. Energy Procedia 2015, 69, 1317-1326. [CrossRef]

15. Gavagnin, G.; Rech, S.; Sánchez, D.; Lazzaretto, A. Optimum design and performance of solar dish micorturbine using tailored component characteristics. Appl. Energy 2018, 231, 660-676. [CrossRef]

16. Starke, A.R.; Lemos, L.F.L.; Boland, J.; Cardemil, J.M.; Colle, S. Resolution of the cloud enhancement problem for one-minute diffuse radiation prediction. Renew. Energy 2018, 125, 472-484. [CrossRef]

17. Photovoltaic Installation at Antarctica by ENEA. Available online: http://www.enea.it/it/Stampa/news/ antartide-una-base-italiana-a-tutte-rinnovabili (accessed on 27 June 2019).

(C) 2019 by the authors. Licensee MDPI, Basel, Switzerland. This article is an open access article distributed under the terms and conditions of the Creative Commons Attribution (CC BY) license (http://creativecommons.org/licenses/by/4.0/). 